\title{
Kinetic Study of Some Active Methylene Compounds by Isoquinolinium Bromochromate
}

\author{
Ravendra Saket $^{1 *}$, K. N. Sharma ${ }^{2}$, Arvind Prasad Dwivedi ${ }^{3}$ \\ ${ }^{1}$ Department of Chemistry, A.P.S. University, Rewa-486003 (M.P.) India \\ ${ }^{2}$ Department of Chemistry, Govt. Girls P.G. College Rewa-486001 (M.P.) India \\ ${ }^{3}$ Department of Chemistry, Govt.Sanjay Gandhi Smrati Auto.P.G.Cpllege, Sidhi M.P.
}

*Corresponding Author: Ravendra Saket, Department of Chemistry, A.P.S. University, Rewa-486003 (M.P. ) India

\begin{abstract}
The kinetics of oxidation of active methylenecompounds namely acetyl acetone (AA) and benzoyl acetone (BA) by Isoquinolinium bromochromate (IQBC) in acetic acid water medium in presence of H2SO4 have been investigated. The observed rate of oxidation is first-order in [IQBC] and [H+] while it is fractional-order in $A A \& B A$. Addition of acetic acid to reaction mixture $(v / v)$ increases reaction velocity constant. The main products of the oxidation are the corresponding triones. Thermodynamic parameters have been computed for the slow step of the proposed mechanism.
\end{abstract}

Key words: oxidation, Active methylene compounds, resonance, substitution, keto-enol.

\section{INTRODUCTION}

The carbonyl compounds especially methylenecompounds exhibit a substitution oxidation, addition etc. types of reactions through enol and enolate in formation because of existence of keto-enol equilibrium, depending on the nature of solvents, resonance and hydrogen bonding. In these compounds the $-\mathrm{CH}_{2}$ - group is sandwiched between two electron attracting $>\mathrm{C}=\mathrm{O}$ groups, being highly acidic, enolize rapidly ${ }^{1}$ and is stabilized by resonance.

The literature contains a few examples of the extensive use of IQBC in acid solutions for oxidation reactions of alcohols ${ }^{2}$, aniline ${ }^{3}$, phenols ${ }^{4}$, aliphatic ${ }^{5}$, ketones etc. Although a lot of works have been reported on the oxidation of enolic form of active methylene compounds by $\mathrm{SeO}_{2},{ }^{6} \mathrm{NCSA},{ }^{7}$ and $\mathrm{NDC}^{8}$. A kinetic study was undertaken to formulate a possible mechanism of acetyl acetone and benzoyl acetone with IQBC in aqueous acetic acid medium in presence of $\mathrm{H}_{2} \mathrm{SO}_{4}$ which has not yet been proposed.

\section{EXPERIMENTAL}

The samples of acetyl acetone (AR) and benzoyl acetone (E. merck) were used, the solutions were prepared in by dissolving their required amount in $\mathrm{CH}_{3} \mathrm{COOH}-\mathrm{H}_{2} \mathrm{O}$ mixture of appropriate composition. The solution of IQBC was obtained by dissolving weighted quantity of synthesized sample in $100 \% \mathrm{CH}_{3} \mathrm{COOH}$ (B.D.H.) and standardized iodometrically. All other necessary reagents employed were of analytical grade.

Progress of reaction was followed by estimating amounts of remaining IQBC at different intervals of time, requisite volumes of standard $\mathrm{IQBC}, \mathrm{H}_{2} \mathrm{SO}_{4}$ and water are taken in $50 \mathrm{ml}$ conical flask, was kept in thermostat of sensitivity $+0.01^{\circ} \mathrm{C}$ to maintain desired temperature.

Requisite volume of active methylene compound was taken in another conical flask which was also kept in same water bath. After half an hour, when reactants had attained temperature of bath, the reaction was initiated by adding specified amount of AA \& BA solutions. Kinetics were followed by removing $2 \mathrm{ml}$ of aliquot after suitable intervals of time and quenching with ice cold water titrated against standard hypo solution using starch as an indicator. The experimental data thus obtained were utilized in fixing order of reaction by usual standard methods. 


\section{RESULTS AND DISCUSSION}

\subsection{Stoichiometry and Product Analysis}

The sets of separate reaction mixtures containing different quantities of IQBC, AA and BA at experimental conditions were allow to react for 48 hours and then analyzed. The remaining IQBC was estimated. The oxidation products were identified as pentane-2, 3,4-trione, and 1-phenyl, bntane-1, 2,3-trione, isoquinoline and chromium of substrates by their spot tests, and also by chemical method. The confirmation was done chromatographically and noting the melting point of their derivatives. The results are in good agreement with 2:3 stoichiometry.

$$
2 \phi \mathrm{HCrO}_{3} \mathrm{Br}+3 \mathrm{R}-\mathrm{C}_{-}-\mathrm{CH}_{2}-\mathrm{R}^{\prime} \stackrel{\mathrm{H}^{+}}{\rightleftharpoons} 3 \mathrm{R}-\mathrm{C}^{2} \mathrm{C}^{2}-\mathrm{R}^{\prime}+2 \phi+2 \mathrm{H} \mathrm{Br}+2 \mathrm{Cr}+3 \mathrm{H}_{2} \mathrm{O}
$$

where, $\phi=$ isoquinoline,

$\mathrm{R}=-\mathrm{CH}_{3}$, and $\mathrm{R}^{\prime}=-\mathrm{COCH}_{3}$ for $\mathrm{AA}$

and $\mathrm{R}=-\mathrm{CH}_{3}$ and $\mathrm{R}^{\prime}=-\mathrm{CO} \mathrm{C}_{6} \mathrm{H}_{5}$ for $\mathrm{BA}$.

The study rules out the presence of free radical inhibitors in the reaction mixture when treated with olefinic acrylonitrile (monomer).

\subsection{Order of Reaction}

The kinetics of the oxidation of AA and BA by IQBC in 30 and $40 \%$ acetic acid at 308 and $313 \mathrm{~K}$ under pseudo first-order conditions was carried out. The linearity of the plots $\log (\mathrm{a}-\mathrm{x})$ versus time yielded parallel lines with almost unit slope indicate first-order dependence [IQBC]. The rate constant have been found to increase in the $[\mathrm{AA}]$ and $[\mathrm{BA}]$ but at higher concentrations declined to follow first-order kinetics i.e. The plot of $1 / \mathrm{k}_{\text {obs }}$ versus $1 /[\mathrm{S}]$ was found linear (Fig.1) with positive slopes on Y-axis less than unity for both the ketones indicating a fractional order dependence of rate (Table 1). A complex kinetics was observed between enolic ketone and active species of IQBC. The rate constant $(\mathrm{k})$ increases with increasing $\left[\mathrm{H}_{2} \mathrm{SO}_{4}\right]$. The unit slope of the graph made between $\log \mathrm{k}$ and $\log \left[\mathrm{H}^{+}\right]$furnishes an evident that the reactions are acid catalyzed and order of reaction with regards to $\mathrm{H}_{2} \mathrm{SO}_{4}$ is one.

\subsection{Effect of Solvent Composition}

The effect of changing solvent binary composition on rate was studied by varying acetic acid from 20$50 \%$. The rate constants (Table 2) suggest that the rate of oxidation increases with increasing acetic acid content of the solvent mixture. The plot of $\log \mathrm{k}$ vs. 1/D was found to be linear with positive slope (Fig. 2) indicating the involvement of a dipole-dipole type of interactions. The influence of ionic strength and primary salt effect was studied by varying concentration of potassium chloride. It was observed that the ionic strength of the medium and salt unaltered the rate of oxidation understudy.

The addition of transition metal cations $\left(\mathrm{Cu}^{++}\right)$as catalyst to reaction shows accelerating effect on reaction velocity. The reactions have been studied in the temperature range $30-50^{\circ} \mathrm{C}$ and using Arrhenius equation, the thermodynamic parameters for equilibrium step and rds have been calculated (Table 3). It may be explained that the fraction of collisions become more stringent and decomposition of activated complex is a quite slow process. $\Delta \mathrm{H}^{\#}$ indicates that the reactions are enthalpy controlled. Further the constancy in the calculated close values of $\Delta G^{\#}$ for the reaction indicate that the iso-kinetic type of mechanism could be operative for the reactions.

\subsection{Mechanism}

The kinetic study was undertaken to formulate a possible reaction mechanism. For this purpose, after studying the overall reaction, the sub divided task into elementary steps would permit confirmation of the proposed hypothesis.

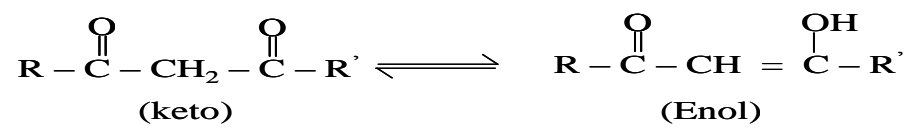


where, $\mathrm{R}-$ and $\mathrm{R}^{\prime}=-\mathrm{CH}_{3}$ for acetyl acetone,

$\mathrm{R}=-\mathrm{CH}_{3}$ and $\mathrm{R}^{\prime}=\mathrm{OC}_{6} \mathrm{H}_{5}$ for benzoyl acetone

2

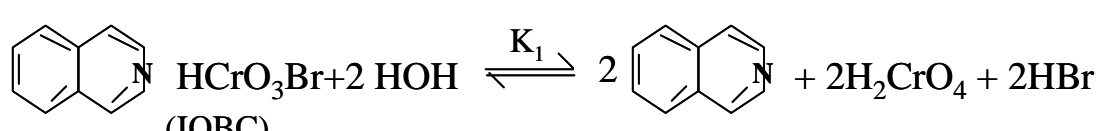
(IQBC)

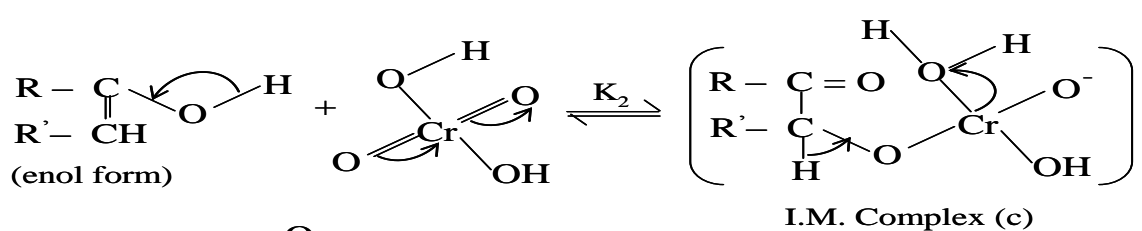

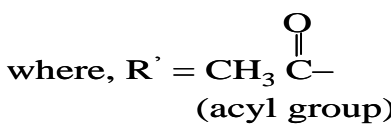

I.M. Complex (c)

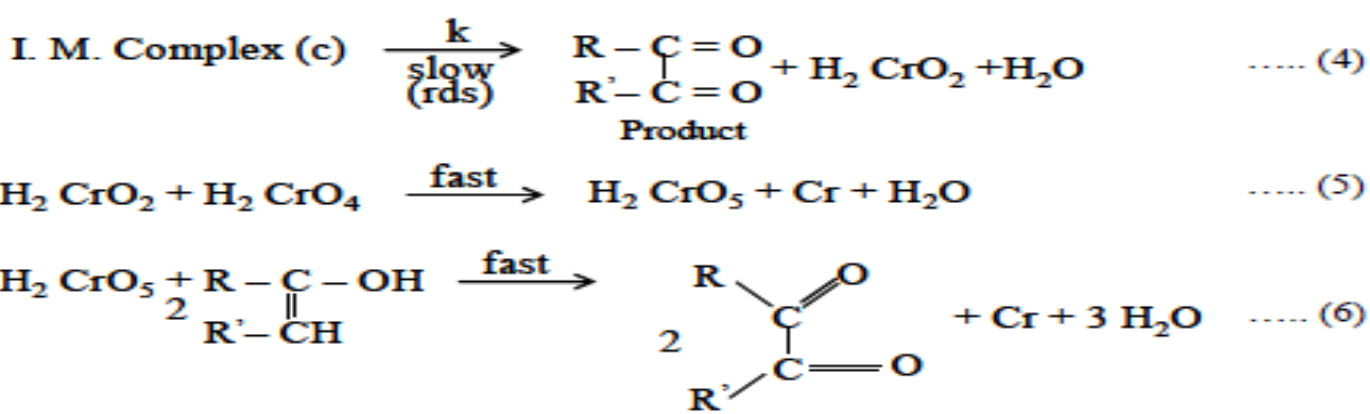

The above mechanism involved attack of an electrophile $\mathrm{H}_{2} \mathrm{CrO}_{4}$ on diketones in a slow process yielding an intermediate complex in rds on double bond of enol. The presence of two carbonyl groups $(>\mathrm{C}=\mathrm{O})$ make the complex susceptible to oxidation by another equivalent of fresh $\mathrm{H}_{2} \mathrm{CrO}_{4}$ that further react with $\mathrm{H}_{2} \mathrm{CrO}_{2}$ to form $\mathrm{H}_{2} \mathrm{CrO}_{5}$ in turn react with two fresh molecules of substrates which is in consonance with the stoichiometric results. Enols are hydroxy compounds, hence like an alcohol attack of $\mathrm{H}_{2} \mathrm{CrO}_{4}$ on enolic $-\mathrm{OH}$ may be formulated. The validity of the rate law may be confirmed by deriving it as

$$
\therefore k_{\text {obs }}=\frac{\mathbf{k ~ K}_{1} \mathbf{K}_{2}[\mathrm{E}]\left[\mathrm{H}^{+}\right]}{[\mathrm{IQ}] \mathrm{K}_{1}+\mathrm{K}_{1}\left[\mathrm{H}^{+}\right]+\mathrm{K}_{1} \mathbf{K}_{2}[\mathrm{E}]+\left[\mathrm{H}^{+}\right]}
$$

The rate expression (7) apparantly account all the experimental results. Similar type of mechanism has already been reported by some research8 workers.

\subsection{Structure and Reactivity}

The observed reactivity was found in order: Acetyl acetone > Benzoyl acetone

The enol content in benzoyl acetone $(89.20 \%)$ is higher than acetyl acetone $(16.40 \%)$ but shows slower rate than AA. This is due to extra stability of chelate ring formation with intramolecular hydrogen bonding of enol form of AA. The replacement of $-\mathrm{CH}_{3}$ group of acetyl acetone by phenyl group $\left(-\mathrm{C}_{6} \mathrm{H}_{5}\right)$ results in an extension of conjugates system in the enol to include the benzene ring which in turn increases the degree of enolisaiton. Hence steric hinderance is more prominent and may cause retardation in addition to resonance and conjugated effect in rate of oxidation. The activity is in accordance with the thermodynamic parameters determined with the fact that bulky group hempers the reactivity thus increasing the $\Delta \mathrm{S} \#$ value.

\section{CONCLUSION}

Kinetic studies demonstrate that binary complex [IQBC....ketones] complex disproportionate in a slow rate determining step to yield trione as the main reaction products. The extra stability of chelate ring formation with hydrogen bonding of enroll form of substrate for slower rate was explained based on resonance and conjugated effect. 
Table1. Effect of varying concentrations of Acetyl acetone and Benzoyl acetone on the rate of reaction $10^{3} \times[\mathrm{IQBC}]\left(\mathrm{mol} \mathrm{dm}^{-3}\right)=2.50(1,2)$;

$10^{3} \times\left[\mathrm{H}^{+}\right]\left(\mathrm{mol} \mathrm{dm}^{-3}\right)=1.0(1), 1.50(2)$;

$\mathrm{CH}_{3} \mathrm{COOH}-\mathrm{H}_{2} \mathrm{O}, \%(\mathrm{v} / \mathrm{v})=30(1), 40$ (2);

Temperature $\mathrm{K}=308$ (1), 313 (2).

\begin{tabular}{|c|c|c|}
\hline \multirow{2}{*}{$\underset{\mathrm{dm}^{-3}}{\left[\text { Substrate] } \times 10^{2} \mathrm{~mol}\right.}$} & \multirow{2}{*}{$\begin{array}{c}\leftarrow \\
\text { Acetyl acetone } \\
(\mathrm{AA})\end{array}$} & $10^{4} k_{o b s}\left(s^{-1}\right)$ \\
\hline & & $\begin{array}{c}\text { Benzoyl acetone } \\
\text { (BA) }\end{array}$ \\
\hline 1.00 & 3.53 & - \\
\hline 1.25 & - & 3.43 \\
\hline 1.50 & 4.40 & 3.85 \\
\hline 2.00 & - & 4.15 \\
\hline 2.50 & 5.05 & 4.82 \\
\hline 4.00 & 5.64 & 5.11 \\
\hline 5.00 & 5.96 & 5.34 \\
\hline
\end{tabular}

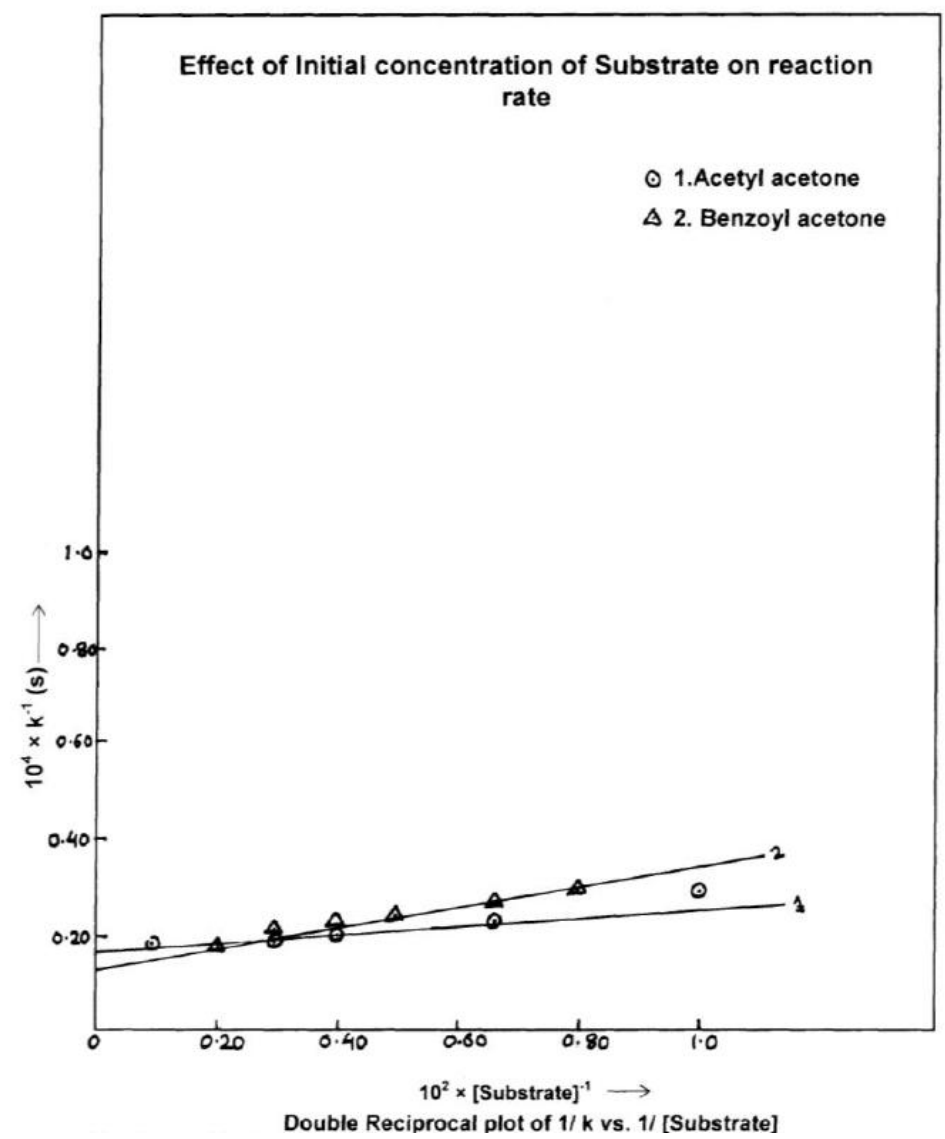

Figure1. $10^{3} \times[\mathrm{IQBC}]\left(\mathrm{mol} \mathrm{dm} \mathrm{m}^{-3}\right)=2.50(1,2) ; 10^{3} \times\left[\mathrm{H}_{2} \mathrm{SO}_{4}\right]\left(\mathrm{mol} \mathrm{dm}^{-3}\right)=1.0(1), 1.50(2) ; \mathrm{HOAc}-\mathrm{H}_{2} \mathrm{O} \%,(\mathrm{~V} / \mathrm{V})$ $=30$ (1), 40 (2);Temp. $K=308(1), 313(2)$.

Table2. Effect of Solvent polarity

$10^{3} \times[\mathrm{IQBC}]\left(\mathrm{mol} \mathrm{dm}^{-3}\right)=2.50(1,2)$;

$10^{2} \times[$ Substrate $]\left(\mathrm{mol} \mathrm{dm}^{-3}\right)=1.50(1,2)$;

$10^{3} \times\left[\mathrm{H}^{+}\right]\left(\mathrm{mol} \mathrm{dm}^{-3}\right)=1.0(1), 1.50(2) ;$

Temperature $\mathrm{K}=308$ (1), 313 (2).

\begin{tabular}{|c|c|c|c|}
\hline \multirow{2}{*}{$\begin{array}{c}\text { HOAc-H } \\
\%(v / v)\end{array}$} & \multirow[t]{2}{*}{$10^{3} / \mathrm{D}$} & \multicolumn{2}{|c|}{$\longleftrightarrow \quad 10^{4} \mathrm{k}_{\text {obs }}\left(\mathrm{s}^{-1}\right) \longrightarrow$} \\
\hline & & Acetyl acetone (AA) & Benzoyl acetone(BA) \\
\hline 20 & 17.17 & 3.23 & 2.08 \\
\hline 30 & 19.15 & 4.40 & 2.75 \\
\hline 40 & 21.98 & 5.20 & 3.85 \\
\hline 50 & 25.64 & 6.45 & 5.37 \\
\hline
\end{tabular}




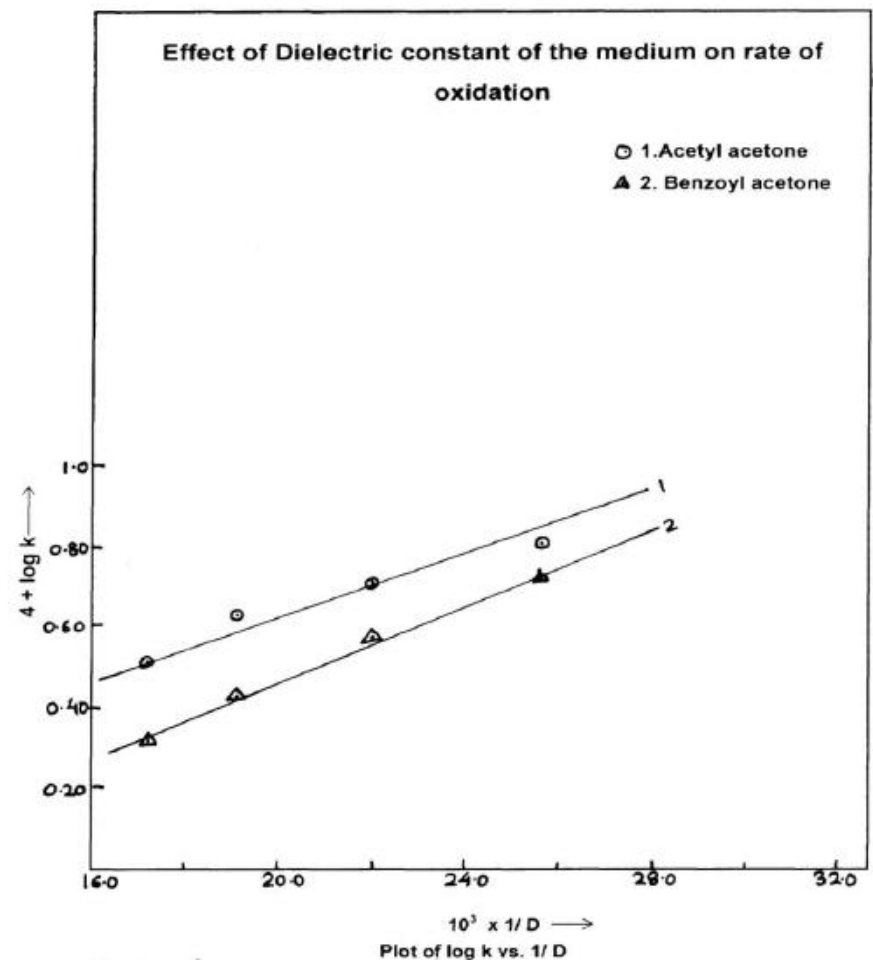

Figure2. $10^{2} \times[$ Substrate $]\left(\mathrm{mol} \mathrm{dm}^{-3}\right)=1.50(1,-2) ; 10^{3} \times[\operatorname{IQBC}]\left(\mathrm{mol} \mathrm{dm}^{-3}\right)=2.50(1,2) ; 10^{3} \times\left[\mathrm{H}_{2} \mathrm{SO}_{4}\right]\left(\mathrm{mol} \mathrm{dm}^{-}\right.$ $\left.{ }^{3}\right)=1.0(1), 1.50(2)$; Temp. $K=308(1), 313(2)$.

Table3. Activation parameters for oxidation of active methylene compounds by IQBC

\begin{tabular}{|c|c|c|c|c|}
\hline \multirow[t]{2}{*}{ Substrate } & \multicolumn{4}{|c|}{ Thermodynamic parameters } \\
\hline & Ea kJ $\left(\mathrm{mol}^{-1}\right)$ & $\Delta \mathbf{H}^{\#} \mathbf{k J}\left(\mathrm{mol}^{-1}\right)$ & $\Delta \mathrm{G}^{\#} \mathrm{~kJ}\left(\mathrm{~mol}^{-1}\right)$ & $-\Delta \mathbf{S}^{\#} \mathrm{JK}^{-1}\left(\mathrm{~mol}^{-1}\right)$ \\
\hline Acetyl acetone (AA) & 56.38 & 51.18 & 84.84 & 116.01 \\
\hline Benzoyl acetone (BA) & 58.93 & 55.65 & 86.59 & 101.20 \\
\hline
\end{tabular}

\section{REFERENCES}

[1] Satyanarayana, N. and Sundaram, E.V, J. Ind. Chem. Soc., 1989, 57, 1076.

[2] Patwari, S.B., Khansole, S.V. and Vibhute, Y.B., J. Iran. Chem. Soc., 2009, 6 (2), 399-404

[3] Patwari, S.B., Khansole, S.V. and Vibhute, Y.B., Chinese Chemical Letters, 2009, 20(3), 256-260.

[4] Patwari, S.B., Khansole, S.V. and Vibhute, Y.B., J. Indian Chem. Soc., 2009, 86 (12), 1343-1346.

[5] Trivedi, Khushboo and Khan, M.U., Elec. J. Adv. Research ${ }^{8}, 2017$ (32), 113-121.

[6] Valechha, N.D. and Pradhan, A., Ind. J. Chem., 1985, 24A, 773-774.

[7] Khan, M.U. Nigam, S.K., Nigam, A., Verma, J.K. and Chauhan, R.P.S., Oxid. Commun, 1995, 18(3), $304-311$.

[8] Patel, Priyanka, Nigam, S.K., and Tiwari, Amit, Int. J. Adv. Sc. Res. , 2017, 2(5), 532.

Citation: Ravendra Saket, et.al. (2019). "Kinetic Study of Some Active Methylene Compounds by Isoquinolinium Bromochromate”. International Journal of Advanced Research in Chemical Science (IJARCS), 6(3), pp.1-5. DOI: http://dx.doi.org/ 10.20431/2349-0403.0603001

Copyright: (C) 2019 Authors. This is an open-access article distributed under the terms of the Creative Commons Attribution License, which permits unrestricted use, distribution, and reproduction in any medium, provided the original author and source are credited. 